\title{
US Institute of Medicine urges mandatory reductions in salt content
}

Published at www.cmaj.ca on Apr. 28

$\mathrm{V}$ oluntary efforts to reduce sodium consumption in the United States have been a failure and it's time for the government to impose gradual but mandatory reductions on the amounts of sodium contained in processed foods and restaurant meals, says a long-awaited report from the US Institute of Medicine.

"The patchwork of voluntary approaches that have been implemented over the years have not worked and have not created the level playing field deemed critical to any successful effort to reduce the sodium content of the overall food supply," the institute said in its report, Strategies to Reduce Sodium Intake in the United States.

"Without major change, hypertension and cardiovascular disease rates will continue to rise, and consumers, who have little choice, will pay the price for inaction," adds the report (www.iom.edu / /media/Files/Report\%20Files/2010 /Strategies-to-Reduce-Sodium-Intake-in -the-United-States/Strategies\%20to $\% 20$ Reduce $\% 20$ Sodium $\% 20$ Intake $\%$ $202010 \% 20 \% 20$ Report\%20Brief.ashx).

The institute, created by Congress to advise the government on health matters, recommended that the US Food and Drug Administration (FDA) set maximum sodium levels that would slowly reduce sodium content across the food supply, "in a way that should avoid making food unpalatable to consumers."

If done right, the institute says, the reductions would be so gradual that consumers wouldn't even notice their taste buds had been retrained to crave less salt in their spaghetti sauce or vegetable soup.

The report got a warm welcome from health public interest groups but its recommendations for mandatory reductions in sodium content aren't likely to be adopted anytime soon.

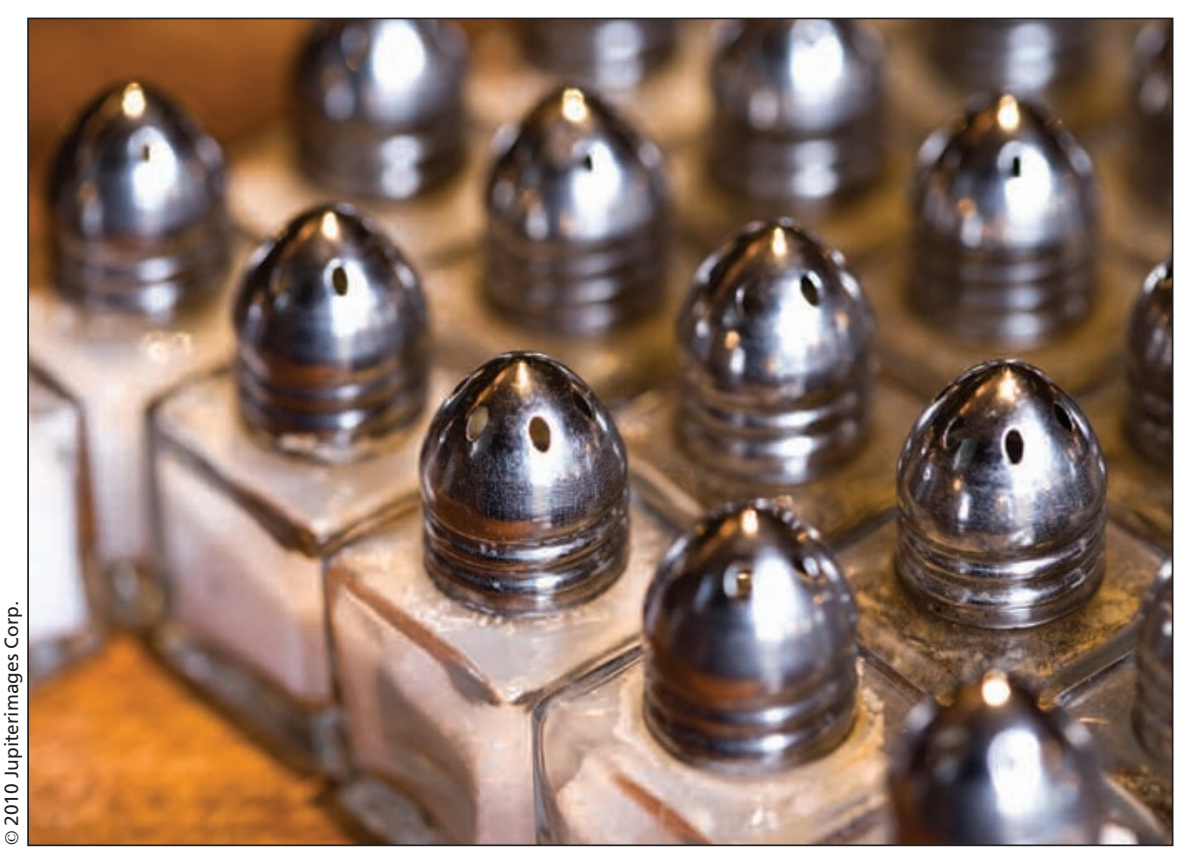

The average American consumes more than $3400 \mathrm{mg}$ of sodium per day, about $50 \%$ more than the recommended limit of $2300 \mathrm{mg}$, according to the US Institute of Medicine.

The FDA pledged to review the report but said in a written statement that it is "not currently working on regulations nor has it made a decision to regulate sodium content in foods at this time." It said the Department of Health and Human Services would set up a working group to "review options and next steps."

FDA Commissioner Dr. Margaret Hamburg said in an interview with the Associated Press that "we believe we can achieve some substantial voluntary reductions. We are shaping a strategy, and that strategy involves working in partnership."

The stakes are high: Too much sodium increases risk for high blood pressure, which can lead to heart disease, stroke, heart failure and kidney disease. And the average American consumes more than $3400 \mathrm{mg}$ of sodium per day, about $50 \%$ more than the recommended limit of $2300 \mathrm{mg}$. Analysts estimate that population-wide reductions in sodium could prevent more than 100000 deaths annually, according to the institute report.

Sodium consumption levels are similar in Canada, where Health Canada plans to publish voluntary targets this year that define the maximum amount of sodium that should be contained in specific types of processed foods (CMAJ 2009. DOI:10.1503/cmaj.1093100).

US Senator Tom Harkin, who pushed for the report and plans to hold hearings, said the time for action was long overdue.

"I understand they want to do it in a phased kind of deal, but I don't want it to be too long," Harkin said in a conference call with reporters.

Harkin stressed that it's not just a matter of prodding Americans to shun their salt shakers, since nearly $80 \%$ of their total salt intake comes from sodium added by food manufacturers and restaurants. 
A number of major food companies have taken steps to voluntarily reduce sodium levels. But the institute report concludes that 40 years of experience shows that voluntary efforts can't solve the problem. Across-the-board sodium standards are needed so "all segments of the food industry would be carrying out the same reductions and none would be at a disadvantage," the report says.

That idea was embraced by the private Center for Science in the Public Interest, which in 2005 petitioned the government to treat salt as a food additive and thus subject to limits.

Michael Jacobson, the center's executive director, says that in confirming that mandatory salt reductions would be more effective, the institute report sends a strong signal to the FDA "that the voluntary approach has been an abysmal failure."

"On the one hand, that would give the FDA a very strong foundation to build regulations," he says. "On the other hand, the regulatory route is complicated. So I think the FDA would naturally gravitate toward a voluntary approach."

It might make sense for the FDA to push the food industry for voluntary reductions while simultaneously working to develop mandatory reductions, Jacobson says. But he cautions that voluntary agreements "can come unglued at any time" as new companies enter the field.

The notion of mandatory sodium limits got a decidedly cool reception from the food industry.

The National Restaurant Association issued a statement saying it would have "concerns about any potential government mandate that creates a one-sizefits-all rule to ingredient standards or sets arbitrary per item limits that do not reflect the complexity of addressing the nation's eating habits and improving overall wellness."

The Grocery Manufacturers Association said it's all for giving consumers healthy choices, but its statement stressed the promise of voluntary measures.

The private Salt Institute called the institute report flawed and reckless, and wants clinical trials before the government embarks on "a population-wide plan which will make human guinea pigs of an entire population." - Nancy Benac, Washington, DC

DOI:10.1503/cmaj.109-3247 